\title{
Comorbid tobacco and other substance use and symptoms of anxiety and depression among hospitalised orthopaedic trauma patients
}

\author{
Sam McCrabb ${ }^{1 *}$ (D), Amanda L. Baker ${ }^{1}$, John Attia ${ }^{1,2,3}$, Zsolt J. Balogh ${ }^{1,4}$, Natalie Lott ${ }^{4}$, Kerrin Palazzi ${ }^{2}$, \\ Justine Naylor ${ }^{5,6}$, Ian A. Harris ${ }^{5,6}$, Christopher M. Doran' ${ }^{7}$, Johnson George ${ }^{8}$, Luke Wolfenden ${ }^{1,9}$, Eliza Skelton ${ }^{1}$ and \\ Billie Bonevski ${ }^{1}$
}

\begin{abstract}
Background: No study has examined the prevalence of tobacco, other substance use, and symptoms of anxiety and depression, and rates of comorbidities among the orthopaedic trauma population, despite the impact they have on recovery from surgery. This study aims to 1) describe the rates of symptoms and substance use; 2) compare rates of symptoms and substance use among smokers versus non-smokers; and 3) examine the relationship between symptoms and substance use with smoking status.

Methods: A cross-sectional survey of orthopaedic trauma patients was conducted in two Australian public hospitals. Demographic characteristics, smoking status, alcohol consumption, recent cannabis use, and symptoms of anxiety and/or depression were examined. Differences between current and non-smokers were compared using Pearson $\mathrm{Chi}^{2}$ tests. Multivariate logistic regression explored variables related to tobacco smoking.

Results: Eight hundred nineteen patients participated. Over one-fifth (21.8\%) identified as a current smoker, half (51.8\%) reported consuming alcohol at hazardous levels in the last 12 months, and about $10 \%$ stated that they had used cannabis in the last 30 days (9.7\%), or experienced symptoms of either anxiety (12.4\%), or depression (12.9\%) in the last two weeks. Over one-fifth of current tobacco smokers (21.8\%) reported drinking heavily in the last 12 months and using cannabis recently. Males, with a lower educational attainment, who were unmarried, had used cannabis recently, and report drinking heavily were more likely to be current smokers.
\end{abstract}

Conclusions: Health behaviour interventions addressing comorbidities are warranted among the orthopaedic trauma population given the high rate of comorbidity and impact these may have on recovery.

Keywords: Smoking, Alcohol, Cannabis, Anxiety, Depression, Comorbidities

\section{Background}

The impact of tobacco smoking on recovery from orthopaedic trauma surgery is well known, with cigarettes linked to increased risk of post-operative infection, [1-3] wound and flap necrosis, [4] and a decrease in the tensile strength of wounds [5]. Despite this, rates of tobacco smoking among orthopaedic trauma patients remain

\footnotetext{
* Correspondence: Sam.McCrabb@newcastle.edu.au

${ }^{1}$ School of Medicine and Public Health, Faculty of Health and Medicine, University of Newcastle, 1 University Drive, Callaghan, NSW 2308, Australia Full list of author information is available at the end of the article
}

higher than that in the general population (37\% vs. $14.5 \%$ in 2014) [6, 7].

When treating tobacco addiction, it is important to identify factors that may undermine quit attempts. Comorbidity, that is, having more than one co-occurring physical or mental health condition at any one time, [8] is known to complicate smoking cessation treatment [9]. Rates of symptoms of anxiety and depression have been found to be higher in orthopaedic trauma patients (39 and $30.5 \%$ respectively) [10] when compared to the general population, [7] and rates of symptoms of anxiety

(c) The Author(s). 2019 Open Access This article is distributed under the terms of the Creative Commons Attribution 4.0 International License (http://creativecommons.org/licenses/by/4.0/), which permits unrestricted use, distribution, and reproduction in any medium, provided you give appropriate credit to the original author(s) and the source, provide a link to the Creative Commons license, and indicate if changes were made. The Creative Commons Public Domain Dedication waiver (http://creativecommons.org/publicdomain/zero/1.0/) applies to the data made available in this article, unless otherwise stated. 
and depression continue to remain high up to two years post-hospital discharge (29.4 and $37.6 \%$, respectively) [11]. Previous research also indicates that rates of hazardous alcohol and recent cannabis use are high in the orthopaedic trauma population [12]. In addition, orthopaedic trauma patients who are readmitted to hospital are more likely to use tobacco, alcohol and other drugs, indicating the need to address the comorbidities within the orthopaedic trauma population [13]. As far as the authors are aware, rates of smoking, alcohol and cannabis use, and symptoms of depression and anxiety have yet to be assessed in the one study among orthopaedic trauma patients.

Guidelines recommend provision of smoking cessation care and nicotine replacement therapy (NRT) during the inpatient stay $[14,15]$. Research suggests that concurrent treatment of co-occurring tobacco and other substance use is more effective than delayed treatment [16]. Concurrent treatment of alcohol use and depression, [17] and depressive symptoms and smoking [18] have been found to be effective. Further, treating tobacco addiction has a positive impact on rates of use of other drugs, with tobacco cessation related to long term reduction or abstinence from other drugs [19]. Thus, if comorbid smoking, alcohol use, cannabis use, and symptoms of depression and anxiety are found to be high among a cohort of hospitalised orthopaeic trauma patients, then there would be implications for the treatment of tobacco use in this setting.

We hypothesise that addressing comorbid health conditions of tobacco smoking (such as other substance use or mental ill-health) when providing smoking cessation care in this setting may: a) improve the health outcome of patients faster, given the negative health impact substance use and mental ill-health can have on recovery; [1-3] and b) decrease health care costs and lengths of hospital admissions, given continued substance use may result in readmission or longer hospital stays, [20] and that are readmitted to hospital are more likely to use substances [13].

Thus, this study aims to characterise an orthopaedic trauma population, and build on prior research in this population $[6,12]$. Specifically, this study aims to:

1. describe the rates of symptoms of anxiety, depression, and substance use (alcohol and cannabis) among patients admitted for an orthopaedic trauma;

2. compare rates of symptoms of anxiety, depression, and alcohol and cannabis use among smokers versus non-smokers; and.

3. examine the relationship between comorbid symptoms of anxiety and depression, alcohol and recent cannabis use with current tobacco use.

\section{Methods}

\section{Study design and setting}

An online cross sectional survey of orthopaedic trauma inpatients was conducted at two Level 1 Trauma public hospitals in New Souths Wales, Australia. Surveys were conducted between April 2015 and September 2016 during the individual's hospital admission.

\section{Participants}

Patients were included if they were: admitted to hospital with a fracture (skull and c-spinal fractures not included); aged 18-80 years; and were able to read and comprehend written English. Patients judged incapable of providing consent (such as those documented to have post-traumatic amnesia, or with a traumatic brain injury) were not approached to take part. All participants provided verbal informed consent prior to commencing the online survey.

Individuals were approached during admission by a research assistant to participate in an online health survey of orthopaedic trauma patients. Research assistants were provided with a list of new orthopaedic trauma admissions each day. Survey numbers were assigned to patients to de-identify their demographic and clinical information from their study results. Patients completed the survey using an internet enabled tablet device during hospital admission. If an individual was too unwell to be seen or was busy with medical staff, they were approached the following day.

\section{Measurements}

Existing validated survey items were used, where possible; [21-27] relevant survey questions are presented in Additional file 1: Supplement 1. Average time to completion of the questionnaire was $15 \mathrm{~min}$. Demographics, current smoking status, alcohol use, cannabis use, and symptoms of anxiety or depression were measured.

Demographic characteristics. Participants were asked to report: gender; age; country of birth; indigenous status; marital status; education; main source of income; household income; and health insurance type.

Smoking status and smoking related variables. Based on previous research; [21] daily, occasional, ex- and non-smoker status was determined. For participants who identified as current smokers, specific questions related to tobacco consumption were asked, [22, 23] with the Heaviness of Smoking Index (HSI) used to determine nicotine dependence ( $0-2$ low, 3-4 moderate, and 5-6 high) [22, 28-30].

Alcohol use. Alcohol consumption in the last 12 months was measured using the 3-item Alcohol Use Disorder Identification Test (AUDIT-C) [24] to screen for hazardous use. Scoring for the AUDIT-C ranges from 0 to 12 with cut-offs of three for females 
(sensitivity 66-73\%, specificity 91-94\%) [31, 32] and four for males used to indicate a hazardous drinker (sensitivity $86 \%$, specificity $72-89 \%)$ [24, 32]. For this study, a non-drinker was categorised as an individual who scored a zero on the AUDIT-C. A score of 1-3 for males or 1-2 for females was regarded as a non- hazardous drinker. Scores above this indicated hazardous drinking.

Cannabis use. Cannabis use during the previous 30 days was measured using an item based on questions asked in the Opiate Treatment Index (OTI) [25].

Anxiety symptoms. The Generalised Anxiety Disorder two item (GAD-2) screening tool [26] was used to estimate symptoms of anxiety in the last two weeks. Scoring for the GAD-2 ranged from 0 to 6 , with a cut off score of three or more indicating anxious symptoms. Specificity for this item ranges from $81 \%$ to $88 \%$ and sensitivity ranges from $59 \%$ to $86 \%$ [26].

Depression symptoms. The Patient Health Questionnaire (PHQ-2), [27] a brief 2-item validated scale was used to estimate rates of symptoms of depression in the last two weeks. Scoring for the PHQ-2 ranges from 0 to 6 , with a cut off score of three or more indicating depressive symptoms. Specificity for this item is $86 \%$ and sensitivity is $79 \%$ for any depressive disorder [27].

\section{Analysis}

All data were stored on secure servers at the University of Newcastle and exported into STATA v13 (StataCorp LP., College Station, TX, USA) for analyses.

Descriptive statistics of participant demographics are presented as numbers and percentages for categorical variables and means (standard deviation; SD) for continuous variables. Rates of smoking were compared among demographic and comorbid groups using Pearson Chi-squared test (categorical) or independent t-test (continuous). Further, a binary logistic regression model was used to examine the associations between demographic characteristics, substance use, and rates of symptoms of anxiety and depression and current tobacco use (compared to non-tobacco use). Variables included in the model were selected a priori and included factors known to be associated with tobacco smoking in medically ill and general populations: age, gender, country of birth, education, marital status, household income, [33-35] anxiety, depression, $[8,36]$ alcohol, and cannabis use. Crude and adjusted odds ratios (OR) with 95\% confidence intervals (CI) and $p$-values are presented. Significance was determined at $p$ $<0.05$. Cronbach alpha statistics are provided for established survey items (AUDIT-C, PHQ-2, and GAD-2) in Additional file 2: Supplement 2.

\section{Results}

Of 1128 orthopaedic trauma patients approached, 819 agreed to participate in the survey (72 refused, 103 were too ill to participate, and 134 were not eligible; response rate of $73 \%$ ). During survey completion, some individuals dropped out due to fatigue. A total of 805 individuals completed the survey (completion rate $98.2 \%)$. Of the 14 participants who did not complete the survey, five were male (nine female), and the average age was 53.6 years (SD 13.4). Two of 13 participants had identified as current tobacco smokers (one participant had dropped out prior to reporting smoking status). Results from this population group has already indicated that interest in quitting smoking is high but that provision of smoking cessation care during admission was low [37]. Six participants reported as non-cannabis users, and of the six who reported their alcohol consumption, two were non-drinkers, two were non- hazardous drinkers and two were hazardous drinkers (the remaining eight participants had dropped out prior to reporting their alcohol or cannabis consumption). The overall Cronbach alpha statistics for AUDIT-C, PHQ-2, GAD-2, were acceptable (ranging from 0.7-0.9), [38] and did not indicate the need to remove any sub-measures.

Demographic characteristics. Table 1 contains a summary of patient demographic information. The mean age was 50.6 years (SD 17.7), the majority of participants were male (59.7\%), born in Australia (84.1\%), and identified as non-Indigenous (94.6\%).

Rates of anxiety or depressive symptoms and substance use. Table 2 reports the rates of anxiety or depressive symptoms and substance use for the total sample.

Differences between current and non-smokers. Table 3 shows the substance use differences between current and non-smokers. Rates of substance use were significantly higher in smokers than non-smokers, as were rates of anxiety and depression.

Rates of concurrent alcohol and cannabis usage for current tobacco smokers. Almost a quarter of current tobacco smokers $(21.8 \%)$ reported drinking heavily in the last 12 months and using cannabis recently (Table 4). A further $48.2 \%$ of current tobacco smokers had reported drinking heavily in the last 12 months, but had not used cannabis in the last 30 days.

Relationship between symptoms of anxiety, depression, and substance use with current smoking status. Table 5 shows that gender, education level, marital status, cannabis use and level of alcohol use were found to be associated with current tobacco smoking. Males had greater odds of being current tobacco users (OR 1.79 $95 \%$ CI $1.14,2.82 ; p=0.01$ ). The odds of being a current smoker were 2.2 times higher in individuals who had an education level of year 10 or less, when compared to those with a tertiary education $(p<0.001)$. Relationship status was found to be significantly associated with current tobacco use, with the odds of being a current 
Table 1 Sociodemographic characteristics of the sample

\begin{tabular}{|c|c|c|}
\hline Characteristic & & $\begin{array}{l}\text { Total }(n=819)^{\mathrm{a}} \\
\mathrm{n}(\%)\end{array}$ \\
\hline \multirow[t]{3}{*}{ Gender } & Male & 489 (59.7\%) \\
\hline & Female & $330(40.3 \%)$ \\
\hline & Missing & 0 \\
\hline \multirow[t]{2}{*}{ Age } & Mean (SD) & $50.6(17.7)$ \\
\hline & Missing & 0 \\
\hline \multirow[t]{3}{*}{ Country of birth } & Australian & $688(84.1 \%)$ \\
\hline & Other & 130 (15.9\%) \\
\hline & Missing & 1 \\
\hline \multirow[t]{5}{*}{ Indigenous status } & Aboriginal & $39(4.8 \%)$ \\
\hline & Torres Strait Islander & $4(0.5 \%)$ \\
\hline & $\begin{array}{l}\text { Both Aboriginal and } \\
\text { Torres Strait Islander }\end{array}$ & $1(0.1 \%)$ \\
\hline & Neither & 774 (94.6\%) \\
\hline & Missing & 1 \\
\hline \multirow[t]{3}{*}{ Marital Status } & $\begin{array}{l}\text { Married/ Defacto/Living } \\
\text { with Partner }\end{array}$ & $471(57.6 \%)$ \\
\hline & $\begin{array}{l}\text { Single/Widowed/ } \\
\text { Separated/Divorced }\end{array}$ & $347(42.4 \%)$ \\
\hline & Missing & 1 \\
\hline \multirow[t]{4}{*}{ Education } & $\begin{array}{l}\text { No formal education/Primary } \\
\text { school/ High school 7-10 }\end{array}$ & $262(32.0 \%)$ \\
\hline & High school 11-12 & $131(16.0 \%)$ \\
\hline & TAFE or trade/University & $425(52.0 \%)$ \\
\hline & Missing & 1 \\
\hline \multirow[t]{6}{*}{ Main source of income } & $\begin{array}{l}\text { Paid employment } \\
\text { (either full or part time) }\end{array}$ & $427(52.2 \%)$ \\
\hline & $\begin{array}{l}\text { Government pension } \\
\text { or benefit }\end{array}$ & $293(35.8 \%)$ \\
\hline & Family member & $29(3.6 \%)$ \\
\hline & Savings or retirement funds & $37(4.5 \%)$ \\
\hline & Other & $32(3.9 \%)$ \\
\hline & Missing & 1 \\
\hline \multirow[t]{5}{*}{ Household Income } & $<\$ 50,000$ per year & $293(36.0 \%)$ \\
\hline & $\$ 51,000-\$ 100,000$ per year & $221(27.1 \%)$ \\
\hline & Over $\$ 100,000$ & $101(12.4 \%)$ \\
\hline & Prefer not to state & $200(24.5 \%)$ \\
\hline & Missing & 4 \\
\hline \multirow[t]{4}{*}{ Insurance type } & $\begin{array}{l}\text { Private health insurance/ } \\
\text { Department of Veteran's } \\
\text { Affairs white or gold card }\end{array}$ & 349 (42.8\%) \\
\hline & Health care concession card & $243(29.8 \%)$ \\
\hline & None of these & $223(27.4 \%)$ \\
\hline & Missing & 4 \\
\hline
\end{tabular}

${ }^{a}$ Some respondents may have dropped out during survey completion due to fatigue
Table 2 Rates of tobacco use, alcohol consumption, recent cannabis use, symptoms of depression (PHQ-2) and anxiety (GAD-2) among the sample

\begin{tabular}{|c|c|c|}
\hline Characteristic & & $\begin{array}{l}\text { Total }(n=819)^{\mathrm{a}} \\
\mathrm{n}(\%)\end{array}$ \\
\hline \multirow[t]{5}{*}{ Smoking status } & Daily smoker & $157(19.6 \%)$ \\
\hline & Occasional Smoker & $18(2.2 \%)$ \\
\hline & Ex-smoker & $235(29.3 \%)$ \\
\hline & Non-smoker & $393(48.9 \%)$ \\
\hline & Missing & 16 \\
\hline \multirow[t]{4}{*}{ AUDIT-C } & Hazardous drinker & $412(51.8 \%)$ \\
\hline & Non-hazardous drinker & $198(24.9 \%)$ \\
\hline & Non-drinker & $185(23.3 \%)$ \\
\hline & Missing & 24 \\
\hline \multirow[t]{3}{*}{ Cannabis use in last 30 days } & Yes & 79 (9.7\%) \\
\hline & No & $732(90.3 \%)$ \\
\hline & Missing & 8 \\
\hline \multirow[t]{4}{*}{ Mix tobacco with cannabis? } & Yes, every time I smoke & $49(6.1 \%)$ \\
\hline & Yes, sometimes & $33(4.1 \%)$ \\
\hline & No, never & $728(89.9 \%)$ \\
\hline & Missing & 9 \\
\hline \multirow[t]{3}{*}{ Depression } & $\begin{array}{l}\text { Above threshold } \\
\text { for depression marker }\end{array}$ & $104(12.9 \%)$ \\
\hline & $\begin{array}{l}\text { Below threshold } \\
\text { for depression marker }\end{array}$ & $705(87.1 \%)$ \\
\hline & Missing & 10 \\
\hline \multirow[t]{3}{*}{ Anxiety } & $\begin{array}{l}\text { Above threshold for } \\
\text { anxiety marker }\end{array}$ & $100(12.4 \%)$ \\
\hline & $\begin{array}{l}\text { Below threshold for } \\
\text { anxiety marker }\end{array}$ & $708(87.6 \%)$ \\
\hline & Missing & 11 \\
\hline \multirow[t]{3}{*}{ Either Depression or Anxiety } & Above threshold & $153(18.9 \%)$ \\
\hline & Below threshold & $655(81.1 \%)$ \\
\hline & Missing & 11 \\
\hline \multirow[t]{3}{*}{ Both Depression and Anxiety } & Above threshold & $51(6.3 \%)$ \\
\hline & Below threshold & $757(93.7 \%)$ \\
\hline & Missing & 10 \\
\hline
\end{tabular}

${ }^{a}$ Total $\mathrm{n}$ may differ as some respondents may have dropped out during survey completion due to fatigue

smoker 1.5 times higher for single/widowed/divorced/ separated individual when compared to an individual in a married/defacto relationship $(p=0.05)$.

The odds of being a current smoker were 6.36 times higher among people who used cannabis $(p<$ $0.001)$, compared to non-users. As well, the odds of being a current smoker were 2.29 times higher in people who reported hazardous drinking when compared to those who reported abstaining from alcohol $(p=0.003)$. 
Table 3 Rates of tobacco use, alcohol consumption (AUDIT-C), recent cannabis use, symptoms of depression (PHQ-2), and anxiety (GAD-2), by smoking status

\begin{tabular}{|c|c|c|c|c|}
\hline Characteristic & & $\begin{array}{l}\text { Smokers }^{a} \\
(n=175) \\
n(\%)\end{array}$ & $\begin{array}{l}\text { Non-smokers }^{\mathrm{a}} \\
(n=628) \\
\mathrm{n}(\%)\end{array}$ & $p$-value \\
\hline \multirow[t]{5}{*}{ Smoking status } & Daily smoker & 157 (89.7\%) & - & \\
\hline & Occasional Smoker & $18(10.3 \%)$ & - & \\
\hline & Ex-smoker & - & $235(37.4 \%)$ & \\
\hline & Non-smoker & - & $393(62.6 \%)$ & \\
\hline & Missing & 0 & 0 & \\
\hline \multirow[t]{4}{*}{ Alcohol consumption } & Non-drinker & $26(15.3 \%)$ & $159(26.1 \%)$ & $<0.001$ \\
\hline & Non- hazardous drinker & $25(14.7 \%)$ & $165(27.1 \%)$ & \\
\hline & Hazardous drinker & 119 (70.0\%) & $286(46.9 \%)$ & \\
\hline & Missing & 5 & 18 & \\
\hline \multirow[t]{3}{*}{ Cannabis use in last 30 days } & No & $122(70.1 \%)$ & $597(96.0 \%)$ & $<0.001$ \\
\hline & Yes & $52(29.9 \%)$ & $25(4.0 \%)$ & \\
\hline & Missing & 1 & 6 & \\
\hline \multirow[t]{4}{*}{ Mix tobacco with cannabis? } & No & $119(68.4 \%)$ & $596(96 \%)$ & $<0.001$ \\
\hline & Yes, every time I smoke & $40(23.0 \%)$ & $9(1.5 \%)$ & \\
\hline & Yes, sometimes & $15(8.6 \%)$ & $16(2.6 \%)$ & \\
\hline & Missing & 1 & 7 & \\
\hline \multirow[t]{3}{*}{ Depression } & Below threshold for depression marker & $141(81.0 \%)$ & $550(88.7 \%)$ & 0.008 \\
\hline & Above threshold for depression marker & $33(19.0 \%)$ & $70(11.3 \%)$ & \\
\hline & Missing & 1 & 8 & \\
\hline \multirow[t]{3}{*}{ Anxiety } & Below threshold for anxiety marker & $140(80.9 \%)$ & $554(89.4 \%)$ & 0.003 \\
\hline & Above threshold for anxiety marker & $33(19.1 \%)$ & $66(10.7 \%)$ & \\
\hline & Missing & 2 & 8 & \\
\hline \multirow[t]{3}{*}{ Either depression or anxiety } & Below threshold & $125(72.3 \%)$ & $516(83.2 \%)$ & 0.001 \\
\hline & Above threshold & $48(27.6 \%)$ & $104(16.8 \%)$ & \\
\hline & Missing & 2 & 8 & \\
\hline \multirow[t]{3}{*}{ Both depression and anxiety } & Below threshold & $155(89.6 \%)$ & $588(94.8 \%)$ & 0.013 \\
\hline & Above threshold & $18(10.4 \%)$ & $32(5.2 \%)$ & \\
\hline & Missing & 2 & 8 & \\
\hline
\end{tabular}

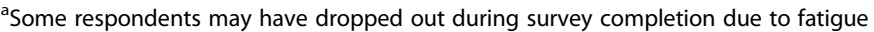

Table 4 Concurrent use of alcohol (AUDIT-C), cannabis and tobacco according to smoking status

\begin{tabular}{llll}
\hline $\begin{array}{lll}\text { Cannabis use in } \\
\text { the last } 30 \text { days }\end{array}$ & Alcohol consumption & \multicolumn{2}{l}{ Smoking status } \\
\cline { 2 - 3 } & & $\begin{array}{l}\text { Smoker } \\
n=170(\%)\end{array}$ & $\begin{array}{l}\text { Non-smoker } \\
n=610(\%)\end{array}$ \\
\hline No & Non-drinker & $21(12.4 \%)$ & $156(25.6 \%)$ \\
& Non- hazardous drinker & $15(8.8 \%)$ & $160(26.2 \%)$ \\
& Hazardous drinker & $82(48.2 \%)$ & $270(44.3 \%)$ \\
Yes & Non-drinker & $5(2.9 \%)$ & $3(0.5 \%)$ \\
& Non- hazardous drinker & $10(5.9 \%)$ & $5(0.8 \%)$ \\
& Hazardous drinker & $37(21.8 \%)$ & $16(2.6 \%)$ \\
\hline
\end{tabular}

\section{Discussion}

Rates of substance use in this population were high, with tobacco smoking and hazardous drinking higher among a sample of orthopaedic trauma patients compared to the general population [7, 39]. Cannabis use and symptoms of anxiety and depression were similar to that found in the general population, $[7,40]$ but not as high as previously identified in an international sample of the orthopaedic trauma population [11, 41]. Reported rates of drinking, cannabis use, and symptoms of anxiety and depression were found to be significantly higher for current smokers. Further, over a fifth $(21.8 \%)$ of current tobacco smokers had engaged in comorbid substance use. The study found that males, who reported drinking heavily, had recently used cannabis, had a lower level of 
Table 5 Crude and adjusted logistic regression of smoking status, with age, gender, marital status, income, depression (PHQ-2), anxiety (GAD-2), cannabis use and alcohol use (AUDIT-C) as explanatory variables

\begin{tabular}{|c|c|c|c|c|c|}
\hline & & Crude & & Adjusted $^{\mathrm{a}}$ & \\
\hline & $\begin{array}{l}\text { Smoker } \\
n=175 \text { (\%) }\end{array}$ & Odds Ratio (95\% Cl) & $P$-value & Odds Ratio (95\% Cl) & $P$-value \\
\hline Age & & $0.98(0.97,0.99)$ & $<0.001$ & $0.99(0.98,1.00)$ & 0.067 \\
\hline Gender & & & $<0.001$ & & 0.012 \\
\hline Female & $46(14.3 \%)$ & Ref. & & Ref. & \\
\hline Male & $129(26.8 \%)$ & $2.20(1.52,3.20)$ & & $1.79(1.14,2.82)$ & \\
\hline Country of birth & & & 0.044 & & 0.673 \\
\hline Other & $19(15.0 \%)$ & Ref. & & Ref. & \\
\hline Australian & $156(23.1 \%)$ & $1.71(1.01,2.87)$ & & $1.13(0.63,2.03)$ & \\
\hline Education & & & $<0.001$ & & 0.002 \\
\hline TAFE Trade/University & $68(16.2 \%)$ & Ref. & & Ref. & \\
\hline High School 11-12 & $28(22.2 \%)$ & $1.47(0.90,2.42)$ & 0.123 & $1.16(0.65,2.08)$ & 0.606 \\
\hline No Formal/Primary School/High School 7-10 & 79 (30.6\%) & $2.28(1.57,3.30)$ & $<0.001$ & $2.20(1.40,3.45)$ & $<0.001$ \\
\hline Marital status & & & $<0.001$ & & 0.045 \\
\hline Married/Defacto & $74(16.0 \%)$ & Ref. & & Ref. & \\
\hline Single/Widowed/ Separated/Divorced & $101(29.8)$ & $2.23(1.59,3.14)$ & & $1.52(1.01,2.30)$ & \\
\hline Household income & & & 0.0051 & & 0.186 \\
\hline Over $\$ 100,000$ & $10(10.2 \%)$ & Ref. & & Ref. & \\
\hline$\$ 51,000-\$ 100,000$ & $45(20.7 \%)$ & $2.30(1.11,4.79)$ & 0.026 & $1.65(0.73,3.70)$ & 0.228 \\
\hline$<\$ 50,000$ & $79(27.5 \%)$ & $3.34(1.65,6.75)$ & $<0.001$ & $2.34(1.03,5.32)$ & 0.043 \\
\hline Prefer not to state & $41(20.7 \%)$ & $2.30(1.10,4.81)$ & 0.027 & $1.68(0.73,3.86)$ & 0.220 \\
\hline Anxiety & & & 0.003 & & 0.263 \\
\hline Negative & $140(20.2 \%)$ & Ref. & & Ref. & \\
\hline Positive & $33(33.3 \%)$ & $1.98(1.25,3.13)$ & & $1.43(0.76,2.67)$ & \\
\hline Depression & & & 0.008 & & 0.680 \\
\hline Below threshold & $141(20.4 \%)$ & Ref. & & Ref. & \\
\hline Above threshold & $33(32.0 \%)$ & $1.84(1.17,2.89)$ & & $1.14(0.61,2.14)$ & \\
\hline Cannabis use & & & $<0.001$ & & $<0.001$ \\
\hline No & $122(17.0 \%)$ & Ref. & & Ref. & \\
\hline Yes & $52(67.5 \%)$ & $10.18(6.08,17.04)$ & & $6.36(3.55,11.37)$ & \\
\hline Alcohol consumption & & & $<0.001$ & & $<0.001$ \\
\hline Non Drinker & $26(14.1 \%)$ & Ref. & & Ref. & \\
\hline Non- hazardous drinker & $25(13.2 \%)$ & $0.93(0.51,1.67)$ & 0.800 & $0.93(0.48,1.80)$ & 0.831 \\
\hline Hazardous drinker & $119(29.4 \%)$ & $2.54(1.60,4.06)$ & $<0.001$ & $2.29(1.34,3.92)$ & 0.003 \\
\hline
\end{tabular}

adjusted for age, gender, country of birth, education, marital status, household income, anxiety, depression, cannabis use, and alcohol consumption. This model also included 'missing' categories for the following variables: anxiety $n=2$, depression $\mathrm{n}=1$, cannabis use $\mathrm{n}=1$, and alcohol consumption $n=5$

educational attainment, and were not in a committed relationship were more likely to be current tobacco users.

The data showing higher comorbid rates of drinking and recent cannabis use among current smokers may warrant addressing these substances together within a single intervention, particularly given that alcohol use has been identified as a predictor of relapse to cigarette smoking [42] and vice versa [43]. Similarly, continued tobacco smoking has been linked to poorer cannabis cessation outcomes. However the impact of cannabis smoking on tobacco cessation is not well explored, [44] and the impact of each other on rates of relapse is not well known [45, 46].

Prochaska et al. [19] found that smoking cessation interventions which address alcohol use also lead to a decrease in other drug use among a sample of polydrug users. Despite this, previous research suggests screening and brief intervention for alcohol use is helpful, however 
infrequently conducted in the clinical setting [47]. While the current provision of smoking cessation care in hospitals remains sub-optimal despite years of smoke-free policy implementation, [48] a lack of staff time is often reported as being a barrier to the provision of care during hospitalisation [49]. The provision of brief advice for substance use, and screening for anxiety and depression may be time consuming for staff who are already over-burdened. Developing an intervention which builds on current policy and guidelines may facilitate intervention implementation. It may be important to include treatment for symptoms of anxiety and depression when treating tobacco use given the rates of these were found to be significantly higher in current smokers. An online intervention may be one way to increase this provision of care. So too, developing a system to refer individuals to the hospital's Drug and Alcohol team, or the inclusion of a specialist nurse or counsellor present on ward to assist with addressing these comorbid issues, may provide a solution. However, as with the implementation of any new intervention to change care practices, feasibility, fidelity, and costing of these needs to be determined.

\section{Strengths and limitations}

The relatively high response rate $(73 \%)$ provides some assurance that this is a representative sample of the orthopaedic trauma population at the two hospitals. Despite this, there may be some limitations with the data as self-report was used to determine rates of substance use and mental ill-health, and may introduce some participant bias to the results, with individual often attaching stigma to the conditions, and sometime unlikely to report rates. For example, as cannabis use is illegal in Australia, it may be that some individuals underreported their use of this substance, with actual rates of use higher than those reported. Given this, these findings may not be generalisable to other orthopaedic trauma populations, with reports of substance use and access to different substances varying from country to country. Further, due to the brevity of the survey, short items were used to determine rates of symptoms of anxiety and depression (however these have previously been found to be reliable) $[26,27]$. As well, it is difficult to determine if the rates of anxiety and depression were present before trauma occurred, or were the result of the traumatic event, given the lack of control group. However, that scores were elevated still indicates the need to address these when tackling tobacco in the hospital setting.

\section{Conclusion}

It is important to take into account the relationship between comorbid health conditions when developing health interventions for orthopaedic trauma patients. Given found comorbidities, and that it is known that the current provision of smoking cessation care has previously been found to be low, it is important to take into account the relationship between alcohol, cannabis, and tobacco use when developing interventions for current tobacco users to help them quit smoking while in hospital, and to prevent relapse upon discharge. Further, it is important to acknowledge and incorporate the characteristics of individuals most likely to engage in the target behaviour. One way to do this may be to develop new interventions which integrate existing guidelines to increase the provision of smoking cessation care, but which also incorporate comorbid conditions and user characteristics. Factoring in psychological techniques to promote positive mental health when addressing tobacco cessation in this population should also be a priority. Addressing these health behaviours may not only promote a faster recovery from surgery, but may also prevent readmission and therefore the cost to the health care system. Health behaviour interventions addressing smoking, substance use and mental ill-health are warranted for the orthopaedic trauma population.

\section{Additional files}

Additional file 1: Supplement 1. Title of data: Survey items, Description of data: Lists all survey items, response options and the references for these. (DOCX $24 \mathrm{~kb}$ )

Additional file 2: Supplement 2. Title of data: Cronbach's alpha statistics, Description of data: Cronbach's alpha statistics for established survey. (DOCX $45 \mathrm{~kb}$ )

Abbreviations

AUDIT-C: Alcohol Use Disorder Identification Test; Cl: Confidence Interval; GAD-2: Generalised Anxiety Disorder two item; NRT: Nicotine Replacement Therapy; OR: Odds Ratio; OTI: Opiate Treatment Index; PHQ-2: Patient Health Questionnaire; SD: Standard Deviation

\section{Acknowledgements \\ SMc is supported by a 50/50 Faculty of Health and Medicine, University of Newcastle PhD Scholarship and a NHMRC research grant. \\ BB is supported by an Australian National Health and Medical Research Council Career Development Fellowship (GNT1063206) and a Faculty of Health and Medicine, University of Newcastle Gladys M Brawn Career Development Fellowship. \\ AB is supported by a National Health and Medical Research Fellowship. ES is supported by a 50/50 Faculty of Health and Medicine, University of Newcastle PhD Scholarship and a NHMRC research grant. We would also like to acknowledge all the staff and patients who made this study possible.}

\section{Funding}

This study was part of a project funded by a grant from the National Health and Medical Research Council (NHMRC) (grant number G1300686). 


\section{Authors' contributions}

SMc led data collection (assisted by NL and JN), analysis and manuscript write-up. AB, BB, JA, NL, ZJB, JN, IAH, CMD, JG, LW and ES oversaw data collection and study progression. KP and JA advised on and assisted with data analysis. All authors contributed to the concept development and design of the project, manuscript drafts and approved of the final manuscript.

\section{Ethics approval and consent to participate}

All participants provided informed verbal consent prior to taking part in the research. This study was approved by the Hunter New England Health Human Ethics department (14/02/19/4.04), with site approval from the University of Newcastle Human Ethics Committee (H-2014-0081) and the South West Sydney Human Ethics Committee (HREC/14/HNE/46; SSA/14/ LPOOL/191).

\section{Consent for publication}

Not applicable.

\section{Competing interests}

The authors declare that they have no competing interests.

\section{Publisher's Note}

Springer Nature remains neutral with regard to jurisdictional claims in published maps and institutional affiliations.

\begin{abstract}
Author details
${ }^{1}$ School of Medicine and Public Health, Faculty of Health and Medicine, University of Newcastle, 1 University Drive, Callaghan, NSW 2308, Australia. ${ }^{2}$ Hunter Medical Research Institute, University of Newcastle, New Lambton, New South Wales 2305, Australia. ${ }^{3}$ Department of General Medicine, John Hunter Hospital, New Lambton Heights, New South Wales 2305, Australia. ${ }^{4}$ Department of Traumatology, John Hunter Hospital, New Lambton, New South Wales 2305, Australia. ${ }^{5}$ Whitlam Orthopaedic Research Centre, Ingham Institute for Applied Medical Research, Liverpool Hospital, Liverpool, New South Wales 2170, Australia. ${ }^{6}$ South Western Sydney Clinical School, Faculty of Medicine, University of New South Wales, Liverpool, New South Wales 2170, Australia. ${ }^{7}$ School of Human, Health and Social Sciences, Central Queensland University, Brisbane, Queensland 4000, Australia. ${ }^{8}$ Centre for Medicine Use and Safety, Monash University, Parkville, Victoria 3052, Australia. 'Hunter New England Population Health, Wallsend, NSW 2287, Australia.
\end{abstract}

Received: 29 July 2018 Accepted: 9 January 2019

Published online: 17 January 2019

\section{References}

1. Sørensen LT. Wound healing and infection in surgery. The clinical impact of smoking and smoking cessation: a systematic review and meta-analysis. Arch Surg. 2012;147(4):373-83.

2. Sørensen LT, Karlsmark T, Gottrup F. Abstinence from smoking reduces incisional wound infection: a randomized controlled trial. Ann Surg. 2003: 238(1):1-5

3. Nasell $\mathrm{H}$, Ottosson $\mathrm{C}$, Tornqvist $\mathrm{H}$, Linde J, Ponzer $\mathrm{S}$. The impact of smoking on complications after operatively treated ankle fractures--a follow-up study of 906 patients. J Orthop Trauma. 2011;25(12):748-55

4. Ahn C, Mulligan P, Salcido RS. Smoking-the bane of wound healing: biomedical interventions and social influences. Adv Skin Wound Care. 2008; 21(5):227-36 quiz 37-8

5. Kanneganti P, Harris JD, Brophy RH, Carey JL, Lattermann C, Flanigan DC The effect of smoking on ligament and cartilage surgery in the knee: a systematic review. Am J Sports Med. 2012;40(12):2872-8.

6. Neptune D, Bonevski B, Enninghorst N, Balogh ZJ. The prevalence of smoking and interest in quitting among surgical patients with acute extremity fractures. Drug Alcohol Rev. 2014;33(5):548-54.

7. ABS. National Health Survey: first results, 2014-15. 2015.

8. Teesson M, Slade T, Mills K. Comorbidity in Australia: findings of the 2007 National Survey of mental health and wellbeing. Aust N Z J Psychiatry. 2009; 43(7):606-14.

9. Hughes JR, Kalman D. Do smokers with alcohol problems have more difficulty quitting? Drug Alcohol Depend. 2006;82(2):91-102.
10. de Moraes VY, Jorge MR, Faloppa F, Belloti JC. Anxiety and depression in Brazilian orthopaedics inpatients: a cross sectional study with a clinical sample comparison. Journal Clin Psych Med Settings. 2010;17(1):31-7.

11. McCarthy ML, MacKenzie EJ, Edwin D, Bosse MJ, Castillo RC, Starr A. Psychological distress associated with severe lower-limb injury. J Bone Joint Surg Am 2003;85-A(9):1689-1697.

12. MacKenzie EJ, Bosse MJ, Kellam JF, Burgess AR, Webb LX, Swiontkowski MF, et al. Characterization of patients with high-energy lower extremity trauma. J Orthop Trauma. 2000;14(7):455-66.

13. Koleszar JC, Childs BR, Vallier HA. Frequency of recidivism in patients with orthopedic trauma. Orthopedics. 2016;39(5):300-6.

14. Cunningham M, Litt J, Zwar N, Borland R, Stillman S, Richmond R. Smoking cessation guidelines for Australian general practice. Aust Fam Physician. 2005;34(6):461.

15. NSW Health. NSW Health Smoke-free Health Care Policy 2015 Sydney, NSW. 2015 [available from: https://www1.health.nsw.gov.au/pds/ ActivePDSDocuments/PD2015 003.pdf.

16. Cooney NL, Litt MD, Sevarino KA, Levy L, Kranitz LS, Sackler H, et al. Concurrent alcohol and tobacco treatment: effect on daily process measures of alcohol relapse risk. J Consult Clin Psychol. 2015;83(2):346-58.

17. Baker AL, Kavanagh DJ, Kay-Lambkin FJ, Hunt SA, Lewin TJ, Carr VJ, et al. Randomized controlled trial of MICBT for co-existing alcohol misuse and depression: outcomes to 36-months. J Subst Abus Treat. 2014;46(3):281-90.

18. Segan CJ, Borland R, Wilhelm KA, Bhar SS, Hannan AT, Dunt DR, et al. Helping smokers with depression to quit smoking: collaborative care with Quitline. MJA. 2011;195(3):S7.

19. Prochaska JJ, Delucchi K, Hall SM. A meta-analysis of smoking cessation interventions with individuals in substance abuse treatment or recovery. J Consult Clin Psychol. 2004;72(6):1144-56.

20. Delgado-Rodríguez M, Medina-Cuadros M, Martínez-Gallego G, GómezOrtega A, Mariscal-Ortiz M, Palma-Pérez S, et al. A prospective study of tobacco smoking as a predictor of complications in general surgery. Infect Control Hosp Epidemiol. 2003;24(1):37-43.

21. Mullins R, Borland R. Changing the way smoking is measured among Australian adults: a preliminary investigation of Victorian data. Quit Evaluation Studies. 91998:163-73.

22. Heatherton TF, Kozlowski LT, Frecker RC, Rickert W, Robinson J. Measuring the heaviness of smoking: using self-reported time to the first cigarette of the day and number of cigarettes smoked per day. Br J Addict. 1989;84(7):791-800.

23. Guillaumier A, Bonevski B, Paul C, D'Este C, Doran C, Siahpush M. Paying the price: a cross-sectional survey of Australian socioeconomically disadvantaged smokers' responses to hypothetical cigarette price rises. Drug Alcohol Rev. 2014;33(2):177-85.

24. Bush K, Kivlahan DR, McDonell MB, Fihn SD, Bradley KA. The AUDIT alcohol consumption questions (AUDIT-C): an effective brief screening test for problem drinking. Ambulatory care quality improvement project (ACQUIP). Alcohol use disorders identification test. Arch Intern Med. 1998;158(16): 1789-95.

25. Darke S, Ward J, Hall W, Heather N, A W. The Opiate Treatment Index (OTI) Researcher's Manual. Sydney: National Drug and Alcohol Research Centre; 1991. Contract No.: 11

26. In Q. The 2-item generalized anxiety disorder scale had high sensitivity and specificity for detecting GAD in primary care. Intern Med. 2007:146:317-25.

27. Lowe B, Kroenke K, Grafe K. Detecting and monitoring depression with a two-item questionnaire (PHQ-2). J Psychosom Res. 2005;58(2):163-71.

28. Lacchetti C, Cohen J, Ashley MJ, Ferrence R, Bull S, de Groh M, et al. Is nicotine dependence related to smokers' support for restrictions on smoking? Nicotine Tob Res. 2001;3(3):257-60.

29. John U, Meyer C, Schumann A, Hapke U, Rumpf HJ, Adam C, et al. A short form of the Fagerstrom test for nicotine dependence and the heaviness of smoking index in two adult population samples. Addict Behav. 2004;29(6):1207-12.

30. Heatherton TF, Kozlowski LT, Frecker RC, Fagerstrom KO. The Fagerstrom test for nicotine dependence: a revision of the Fagerstrom tolerance questionnaire. Br J Addict. 1991:86(9):1119-27.

31. Bradley KA, Bush KR, Epler AJ, Dobie DJ, Davis TM, Sporleder JL, et al. Two brief alcohol-screening tests from the alcohol use disorders identification test (AUDIT): validation in a female veterans affairs patient population. Arch Intern Med. 2003:163(7):821-9.

32. Bradley KA, DeBenedetti AF, Volk RJ, Williams EC, Frank D, Kivlahan DR. AUDIT-C as a brief screen for alcohol misuse in primary care. Alcoh Clin Exp Res. 2007;31(7):1208-17. 
33. Castillo RC, Bosse MJ, MacKenzie EJ, Patterson BM, Group LS. Impact of smoking on fracture healing and risk of complications in limb-threatening open tibia fractures. J Orthop Trauma. 2005;19(3):151-7.

34. Ostroff JS, Jacobsen PB, Moadel AB, Spiro RH, Shah JP, Strong EW, et al. Prevalence and predictors of continued tobacco use after treatment of patients with head and neck-Cancer. Cancer. 1995;75(2):569-76.

35. Bonevski B, Regan T, Paul C, Baker AL, Bisquera A. Associations between alcohol, smoking, socioeconomic status and comorbidities: evidence from the 45 and up study. Drug Alcohol Rev. 2014;33(2):169-76.

36. Kay-Lambkin F, Edwards S, Baker A, Kavanagh D, Kelly B, Bowman J, et al. The impact of tobacco smoking on treatment for comorbid depression and alcohol misuse. Int J Ment Health Ad. 2013;11(6):619-33.

37. McCrabb S, Baker AL, Attia J, Balogh ZJ, Lott N, Palazzi K, et al. Smoking, quitting and the provision of smoking cessation support: A survey of orthopaedic trauma patients. J Orthop Trauma. 2017.

38. Tavakol M, Dennick R. Making sense of Cronbach's alpha. Int J Med Educ. 2011;2:53-5.

39. Proude EM, Britt $H$, Valenti L, Conigrave KM. The relationship between selfreported alcohol intake and the morbidities managed by GPs in Australia. BMC Fam Pract. 2006;7(1):17.

40. AlHW. National Drug Strategy Household Survey detailed report: 2013. 2014.

41. Massey GM, Dodds HN, Roberts CS, Servoss TJ, Blondell RD. Toxicology screening in orthopedic trauma patients predicting duration of prescription opioid use. J Addict Dis, 2005;24(4):31-41.

42. Lisha NE, Carmody TP, Humfleet GL, Delucchi KL. Reciprocal effects of alcohol and nicotine in smoking cessation treatment studies. Addict Behav. 2014;39(3):637-43.

43. Kahler CW, Borland R, Hyland A, McKee SA, Thompson ME, Cummings KM. Alcohol consumption and quitting smoking in the international tobacco control (ITC) four country survey. Drug Alcohol Depend. 2009:100(3):214-20

44. Peters EN, Budney AJ, Carroll KM. Clinical correlates of co-occurring cannabis and tobacco use: A systematic review. Addiction. 2012;107(8): 1404-17.

45. Moore BA, Budney AJ. Tobacco smoking in marijuana-dependent outpatients. J Subst Abus. 2001:13(4):583-96.

46. Lee DC, Budney AJ, Brunette MF, Hughes JR, Etter J-F, Stanger C. Outcomes from a computer-assisted intervention simultaneously targeting cannabis and tobacco use. Drug Alcohol Depend. 2015;155:134-40.

47. Kypri K, Langley JD, Saunders JB, Cashell-Smith ML, Herbison P. Randomized controlled trial of web-based alcohol screening and brief intervention in primary care. Arch Intern Med. 2008;168(5):530-6.

48. Slattery C, Freund M, Gillham K, Knight J, Wolfenden L, Bisquera A, et al. Increasing smoking cessation care across a network of hospitals: an implementation study. Implement Sci. 2015;11:28.

49. Twardella D, Brenner H. Lack of training as a central barrier to the promotion of smoking cessation: a survey among general practitioners in Germany. Eur J Pub Health. 2005;15(2):140-5.

Ready to submit your research? Choose BMC and benefit from:

- fast, convenient online submission

- thorough peer review by experienced researchers in your field

- rapid publication on acceptance

- support for research data, including large and complex data types

- gold Open Access which fosters wider collaboration and increased citations

- maximum visibility for your research: over $100 \mathrm{M}$ website views per year

At $\mathrm{BMC}$, research is always in progress.

Learn more biomedcentral.com/submissions 